\title{
Active Comb Filter Using Operational Transconductance Amplifier
}

\author{
Rajeev Kumar Ranjan, Surya Prasanna Yalla, Shubham Sorya, and Sajal K. Paul \\ Department of Electronics Engineering, Indian School of Mines, Dhanbad, Jharkhand 826004, India \\ Correspondence should be addressed to Sajal K. Paul; sajalkpaul@rediffmail.com
}

Received 7 February 2014; Revised 15 April 2014; Accepted 23 April 2014; Published 22 May 2014

Academic Editor: Jiun-Wei Horng

Copyright (C) 2014 Rajeev Kumar Ranjan et al. This is an open access article distributed under the Creative Commons Attribution License, which permits unrestricted use, distribution, and reproduction in any medium, provided the original work is properly cited.

A new approach for the design of an active comb filter is proposed to remove the selected frequencies of various signals. The proposed filter is based on only OTAs and capacitors, hence suitable for monolithic integrated circuit implementation. The workability of the circuit is tested using PSPICE for test signals of $60,180,300$, and $420 \mathrm{~Hz}$ as in ECG signal. The results are given in the paper and found to agree well with theory.

\section{Introduction}

When harmonics of a certain frequency components are coupled into the circuit or the signal transmission line of an instrumentation system, the data acquired may suffer from harmonic interference. The power line interference is a common type of interference for various types of signals such as biomedical signals. There are basically two components in power line interferences, namely, electric field interference and magnetic field interference. Electric field interference generates spikes at $50 / 60 \mathrm{~Hz}$ frequency, whereas magnetic field which is generated due to the transformer in the power supply causes interference to generate harmonic frequencies of the fundamental. As an example, the source of these interferences is present in the entire clinic $[1,2]$, where a number of biomedical instruments run on AC power line. Hence physiological signal gets corrupted by power line frequency and its harmonics. The interference may be removed by both digital and analog filtering techniques [19].

Operational amplifiers are the most popular building block for analog circuit design. However, op-amp has limitations in bandwidth and slew rate which lead the analog designer to search for other possibilities [5-7, 10-17]. Recently operational transconductance amplifier (OTA) has been found to be one of the most significant building blocks in analog signal processing. In high-frequency continuoustime filters, OTA-C filters have often been employed since OTAs provide high bandwidth, high slew rate, and a transconductance gain $(G)$ which can be electronically controlled using a bias current. Hence the circuits developed using OTAs are most likely to possess intrinsic electronic control of parameters such as the cutoff frequency, quality factor, gain of a filter or frequency of oscillation, and the condition of oscillation of an oscillator.

In this paper a new analog comb filter based on notch filter is proposed. The presented filter is developed using all OTAs and capacitors. Hence it is an OTA-C comb filter and suitable for IC implementation. The parameters of the comb filter can be easily tuned electronically using bias current of OTAs.

\section{Circuit Description}

The circuit of second order passive notch filter is shown in Figure 1.

The routine analysis gives voltage transfer function $H(s)$ as

$$
H(s)=\frac{s^{2} L C+1}{s^{2} L C+s C R+1} .
$$




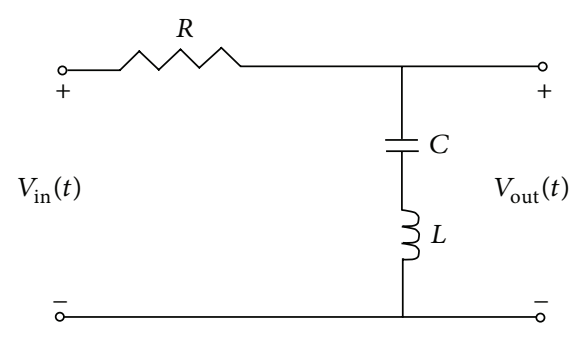

FIGURE 1: RLC circuit of notch filter.

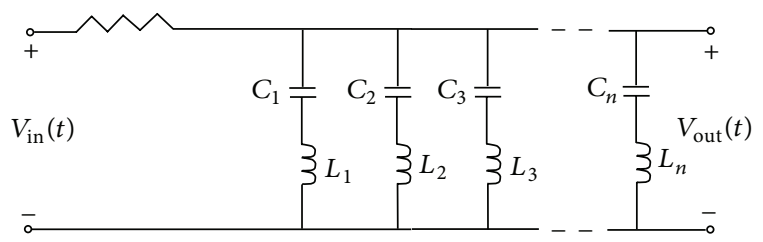

Figure 2: Comb filter using a basic RLC circuit.

The parameters of notch filters are obtained as

$$
\begin{gathered}
\omega_{0}=\frac{1}{\sqrt{L C}}, \\
Q_{0}=\frac{1}{R} \sqrt{\frac{L}{C}}, \\
\Delta f=\frac{R}{L} .
\end{gathered}
$$

2.1. Proposed Active Comb Filter. The extension of $L-C$ section of circuit in Figure 1 gives a comb filter as shown in Figure 2. It can remove $n$-number of harmonics of the power line interference, which corrupt the input signal $V_{\text {in }}(t)$.

The routine analysis of the circuit in Figure 2 results in a voltage transfer function of the active comb filter as

$$
H(s)=\frac{1}{R \sum_{k=1}^{n}\left(s C_{k} /\left(s^{2} L_{k} C_{k}+1\right)\right)+1} .
$$

The $K$ th notch filter is used to eliminate the $K$ th harmonic component from the input signal $V_{\text {in }}(t)$. The transfer function of the $K$ th notch filter is obtained as

$$
H^{k}(s)=\frac{1}{\left(s C_{k} R /\left(s^{2} L_{k} C_{k}+1\right)\right)+1} .
$$

It is well known that the implementation of inductance in integrated circuits is very difficult or almost impossible. The passive resistance $(R)$ is also not encouraged in integrated circuit implementation. Hence to ease the integrated circuit implementation, the proposed notch filter is implemented based on a new active element, namely, operational transconductance amplifier (OTA).

Operational transconductance amplifier (OTA) is an active current mode building block. It is widely used block in integrated circuit technique and suitable for various applications. It consists of an input differential pair and an output current mirror. The input of OTA is voltage and output is

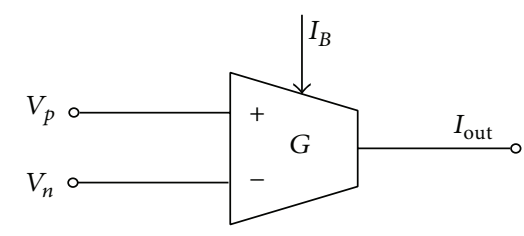

Figure 3: Symbol of OTA.

current. It has higher bandwidth and slew rate than op-amp. The transconductance gain $(G)$ of OTA can be controlled electronically by bias current over a wide range. The symbolic representation of an OTA is given in Figure 3 and internal structure in Figure 4. The transconductance gain for CMOS based OTA is expressed as

$$
G=B \sqrt{2 \mu C_{\mathrm{ox}}\left(\frac{w}{L}\right) I_{B}}
$$

where $B$ is constant, $\mu$ is the mobility of electron, $C_{o x}$ is oxide capacitance, $I_{B}$ is biasing current which is controlled by biasing voltage $V_{\text {con }}, W$ is channel width, and $L$ is the channel length of the transistor.

The circuit of notch filter using all OTAs and capacitors is shown in Figure 5. The resistance $(R)$ and inductance $(L)$ are expressed as

$$
R=\frac{1}{G_{R}}, \quad L=\frac{C_{L}}{G_{L}^{2}},
$$

where $G_{R}$ and $G_{L}$ are the transconductance of the OTAs, which implements $R$ and $L$, respectively.

It reveals that the value of resistance $(R)$ and inductance (L) may be varied using bias current of respective OTAs. Hence, $\omega_{o}, Q_{o}$, and bandwidth $(\Delta f)$ can be tuned electronically with the bias current of OTAs. It is also evident that $Q_{o}$ can be tuned independently of $\omega_{o}$ by $R$. The generalized proposed OTA-C comb filter which can absorb $n$ number of unwanted frequencies is shown in Figure 6. The expressions of the characteristic parameters of each notch filter are modified as

$$
\begin{aligned}
& \omega_{\text {on }}=\frac{1}{\sqrt{L_{n} C_{n}}}=\sqrt{\frac{G_{L n}^{2}}{C_{L n} C_{n}}}=\frac{G_{L n}}{\sqrt{C_{L n} C_{n}}}, \\
& Q_{\text {on }}=\frac{1}{R} \sqrt{\frac{L_{n}}{C_{n}}}=G_{R} \sqrt{\frac{C_{L n}}{G_{L n}^{2} C_{n}}}=\frac{G_{R}}{G_{L n}} \sqrt{\frac{C_{L n}}{C_{n}}}, \\
& \Delta f_{n}=\frac{G_{L n}^{2}}{G_{R} C_{L n}} .
\end{aligned}
$$

It is evident that once the values of $C_{n}$ and $C_{L n}$ are fixed as per requirement, the notch frequencies can still be tuned by varying $G_{L n}$ using bias currents of $n$th set of OTAs. The same is also true for quality factor $\left(Q_{\text {on }}\right)$ and bandwidth $\left(\Delta f_{n}\right)$.

\section{Simulation and Result}

The OTA in Figure 4 has been simulated using PSPICE in $0.5 \mu \mathrm{m}$ CMOS Technology. The dimensions of the MOS are 


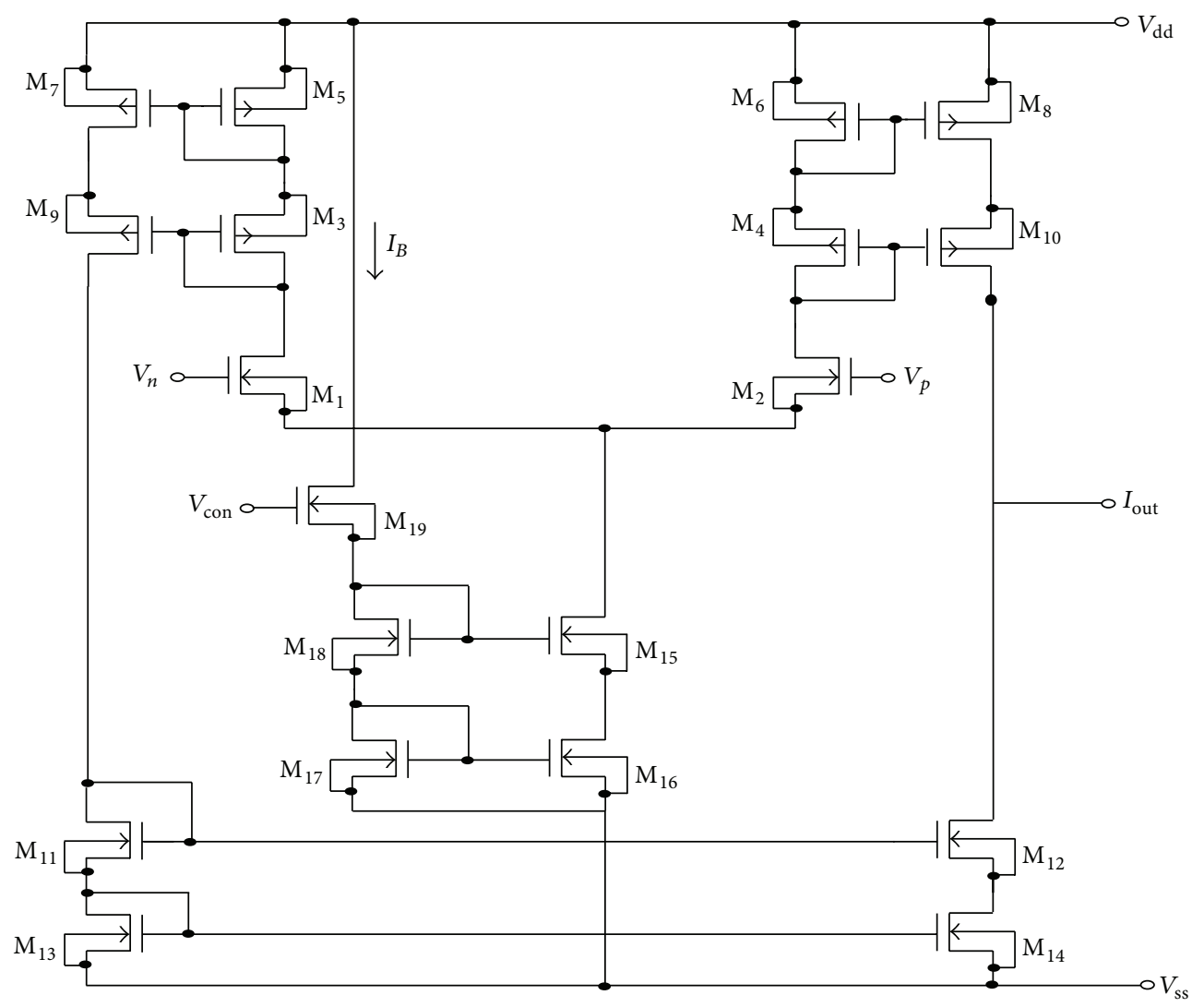

FIGURE 4: Internal structure of OTA [4].

TABLE 1: MOS dimensions [4].

\begin{tabular}{lcc}
\hline MOS & Dimensions of MOS transistors & \\
$\mathrm{M}_{1}, \mathrm{M}_{2}, \mathrm{M}_{11}, \mathrm{M}_{12} \mathrm{M}_{13}, \mathrm{M}_{14}, \mathrm{M}_{15}, \mathrm{M}_{16}, \mathrm{M}_{17}, \mathrm{M}_{18}$, and $\mathrm{M}_{19}$ & $W(\mu \mathrm{m})$ & $L(\mu \mathrm{m})$ \\
$\mathrm{M}_{3}, \mathrm{M}_{4}, \mathrm{M}_{5}, \mathrm{M}_{6}, \mathrm{M}_{7}, \mathrm{M}_{8}, \mathrm{M}_{9}$, and $\mathrm{M}_{10}$ & 5 & 3 \\
\hline
\end{tabular}

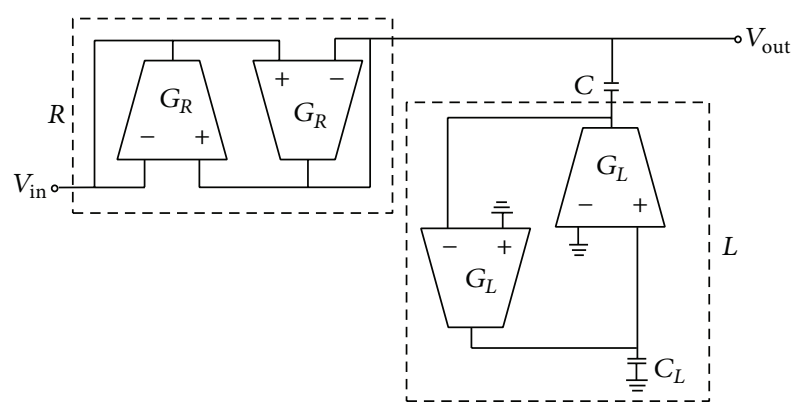

FIgURE 5: Realization of OTA-C notch filter.

given in Table 1 [4]. The supply voltages used for simulation are $V_{\mathrm{dd}}=5 \mathrm{~V}$ and $V_{\mathrm{ss}}=-5 \mathrm{~V}$. The results of simulations are shown in Figures 7, 8, and 9.

Physiological signal such as ECG signal is known to contain the power line frequency and its harmonics along with the actual physiological signal. Hence as an example, the proposed comb filter is designed for $n=4$ to show its performance to remove undesired power line signals of fundamental frequency of $60 \mathrm{~Hz}$ and its odd harmonics 180 , 300 , and $420 \mathrm{~Hz}$ in ECG signal. As it is a low-frequency operation, a low noise and low distortion OTA as presented in Figure 4 suitable for low-frequency application [4] is used. The values of capacitors used are $C_{1}=998.85 \mathrm{nF}, C_{2}=$ $110.98 \mathrm{nF}, C_{3}=39.95 \mathrm{nF}, C_{4}=20.38 \mathrm{nF}$, and $C_{L 1}=C_{L 2}=$ $C_{L 3}=C_{L 4}=21 \mathrm{nF}$ and $R$ is adjusted to $100 \mathrm{k} \Omega$ by biasing current of corresponding OTAs. The frequency response of the output of the comb filter is shown in Figure 10. It verifies that the simulated response matches perfectly the theoretical result. The time responses of the input having frequencies $60,180,300$, and $420 \mathrm{~Hz}$ signals and their corresponding outputs are shown in Figures 11, 12, 13, and 14, respectively. It reveals that the output is almost insignificant at the set (rejection) frequency of the comb filter. To know the quality of the output and dynamic range at the passband, the total harmonic distortion has been obtained for a signal at $100 \mathrm{~Hz}$ as shown in Figure 15. It indicates that \% THD is very low up to $4.5 \mathrm{~V}$ (peak to peak). It indicates that the dynamic 


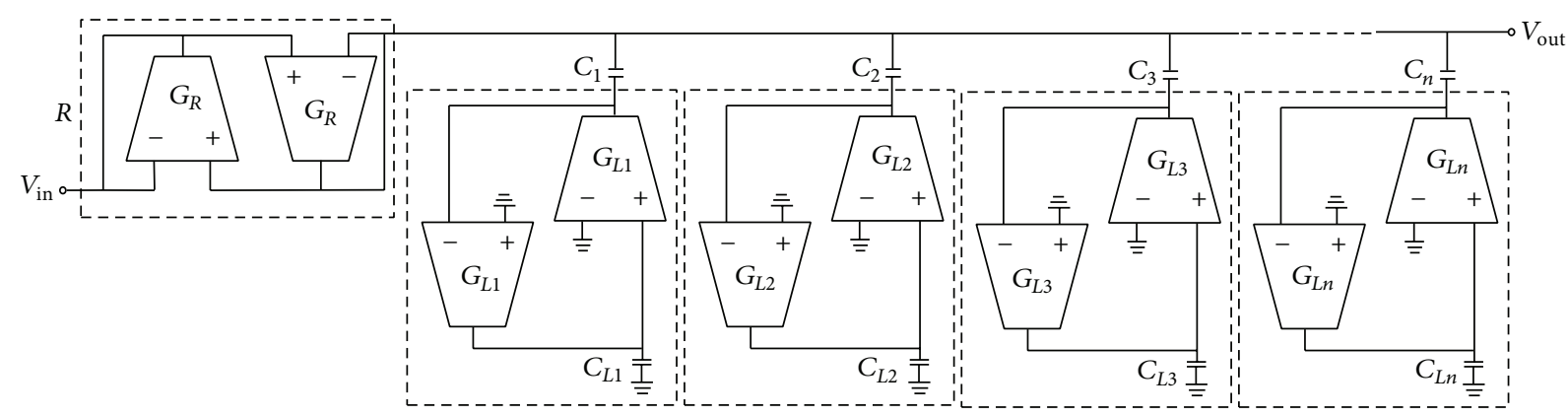

Figure 6: Generalized OTA-C comb filter.

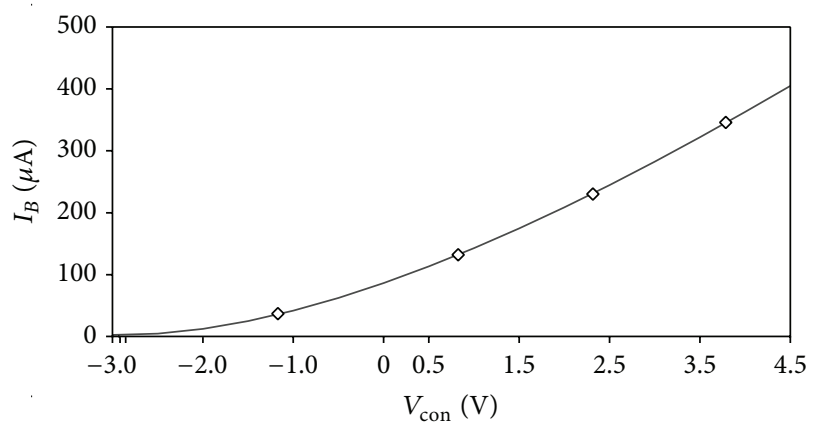

Figure 7: Variation of biasing current $I_{B}$ with control voltage $V_{\text {con }}$.

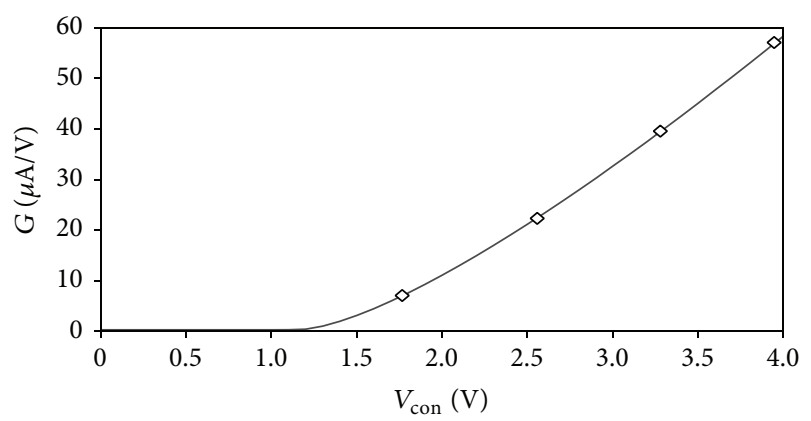

FIGURE 8: Variation of transconductance $G$ with control voltage $V_{\text {con }}$.

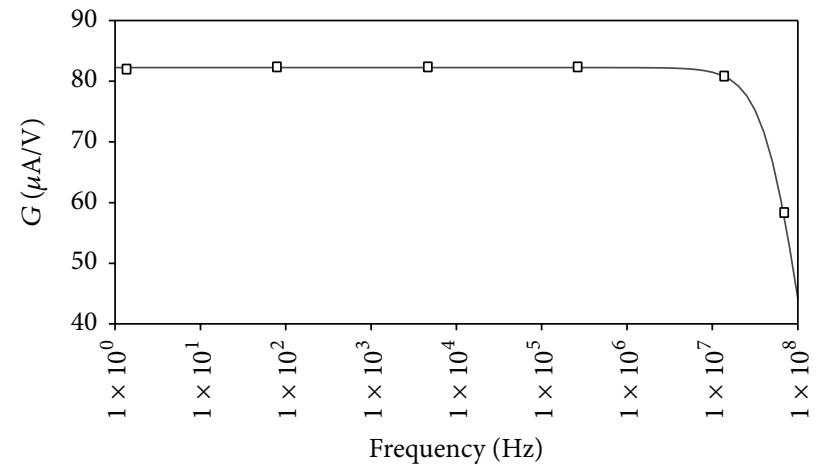

FIGURE 9: Frequency response of OTA transconductance for bias current $I_{B}=206.3 \mu \mathrm{A}$.

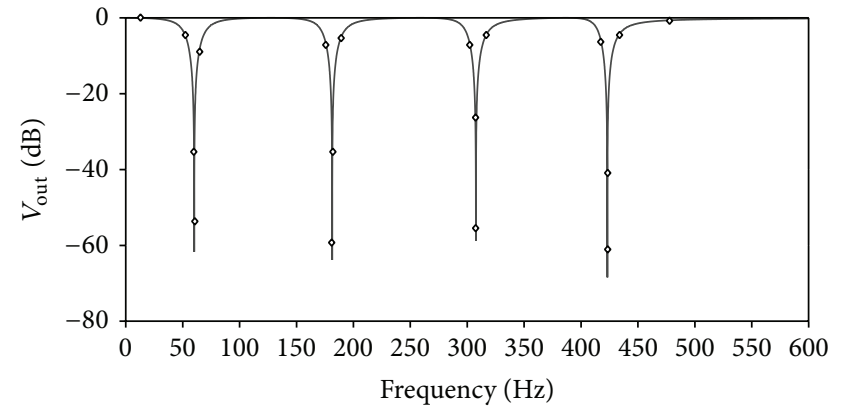

FIGURE 10: Simulated result of proposed comb filter.

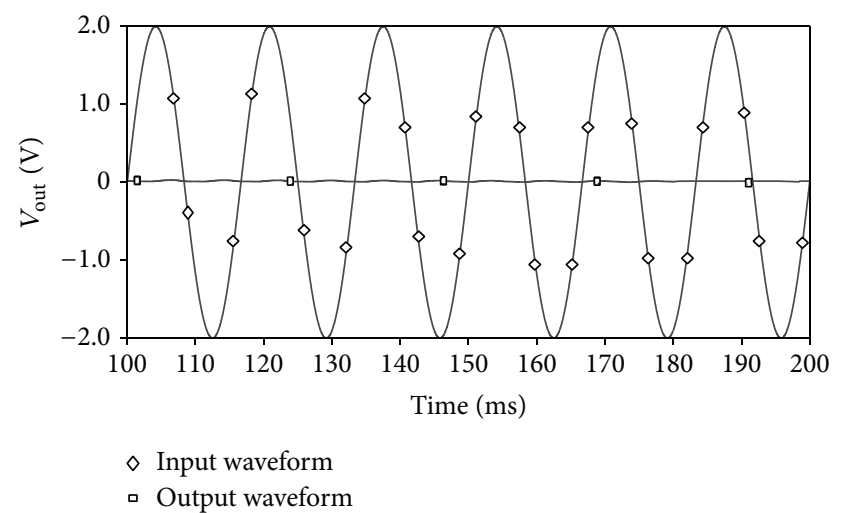

FIGURE 11: Input and output response at $60 \mathrm{~Hz}$.

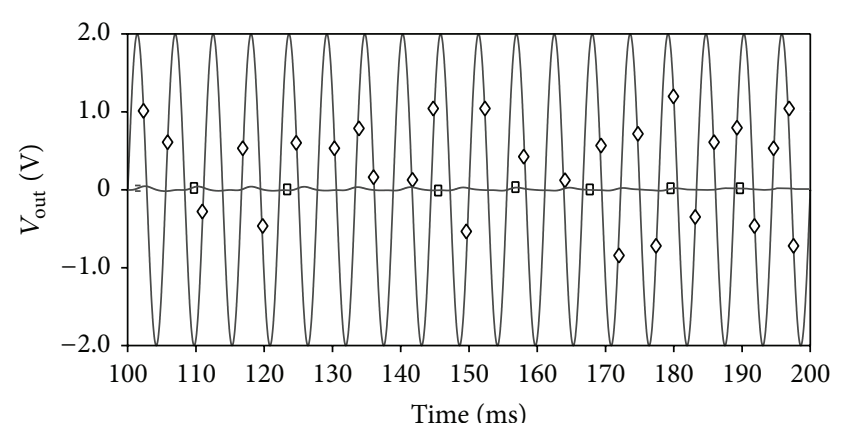

$\diamond$ Input waveform

口 Output waveform

Figure 12: Input and output response at $180 \mathrm{~Hz}$. 


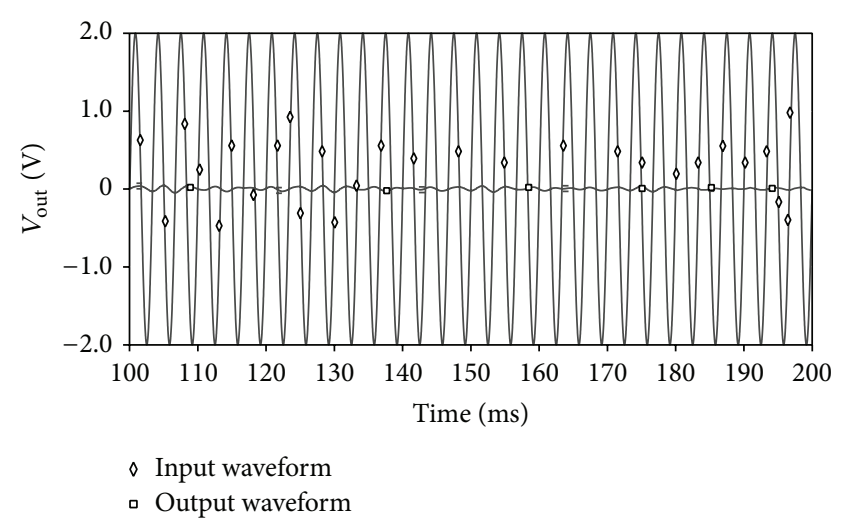

FIGURE 13: Input and output response at $300 \mathrm{~Hz}$.

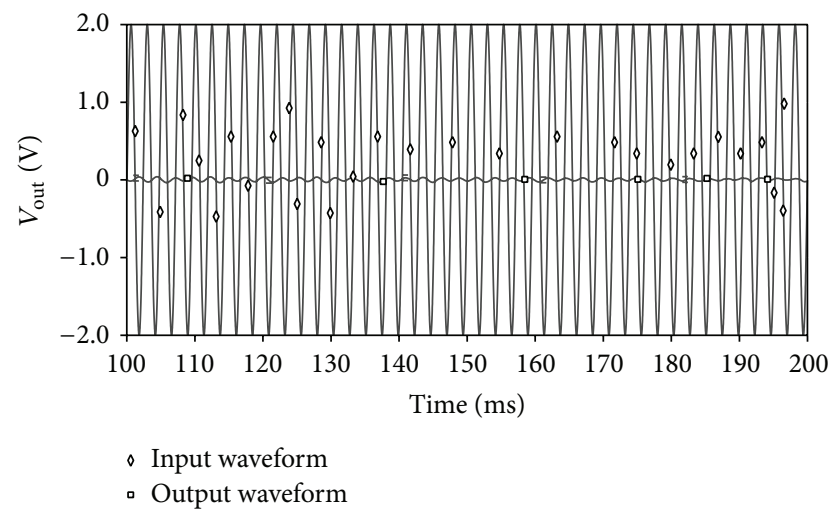

FIgURE 14: Input and output response at $420 \mathrm{~Hz}$.

range is wide. The noise characteristic of the proposed circuit has been analyzed. The proposed comb filter is designed to reject $60 \mathrm{~Hz}, 180 \mathrm{~Hz}, 300 \mathrm{~Hz}$, and $420 \mathrm{~Hz}$ signals. The noise of the circuit for an input signal of $100 \mathrm{KHz}$ is obtained as $484 \mathrm{nV} / \sqrt{\mathrm{Hz}}$ at the input and $482 \mathrm{nV} / \sqrt{\mathrm{Hz}}$ at output. However when it is tested with input signal of $60 \mathrm{~Hz}$, the input noise is obtained as $987.7 \mathrm{nV} / \sqrt{\mathrm{Hz}}$ and output noise of $0.45 \mathrm{nV} / \sqrt{\mathrm{Hz}}$. It shows a significant reduction of noise at stopband. The circuit consumes a power of $21.5 \mathrm{~mW}$. Moreover, $3 \mathrm{~dB}$ cutoff frequency of the OTA transconductance is $f_{3 \mathrm{~dB}}=65.97 \mathrm{MHz}$ for the biasing current of $I_{B}=206.3 \mu \mathrm{A}$; the same is shown in Figure 9. Therefore the operation of the proposed circuit is limited to $65.97 \mathrm{MHz}$.

\section{Conclusion}

A new active comb OTA-C filter is proposed. The workability of the circuit has been tested by using PSPICE in $0.5 \mu \mathrm{m}$ CMOS Technology. The simulated and theoretical results agreed quite well. The comparison of the proposed work with the reported publications $[8,9]$ reveals the following features in favour of proposed circuit. (i) It indicates that \% THD is very low up to the input signal of $4.5 \mathrm{~V}$ (Peak-to-Peak). (ii) Although the number of active components is higher in comparison to $[8,9]$, the number of passive components

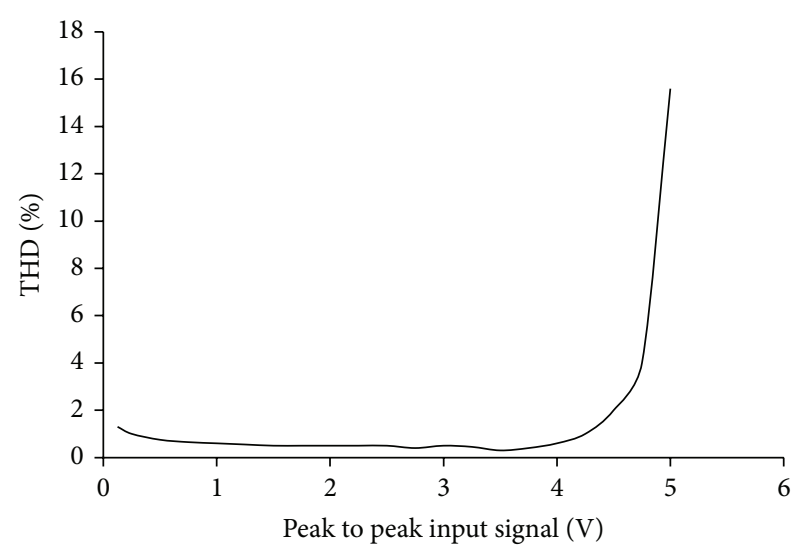

FIGURE 15: \%THD of comb filter.

is remarkably less. (iii) Parameters of filters such as $\omega_{\text {on }}$, $Q_{\text {on }}$, and $\Delta f_{n}$ can be electronically controlled by varying bias current of OTAs. (iv) Moreover, $Q_{\mathrm{on}}$ can be conveniently varied independent of $\omega_{\text {on }}$ by bias current of OTAs, which is very much useful to achieve high selectivity.

\section{Conflict of Interests}

The authors declare that there is no conflict of interests regarding the publication of this paper.

\section{References}

[1] J. C. Huhta and J. G. Webster, "60-Hz interference in electrocardiography," IEEE Transactions on Biomedical Engineering, vol. 20, no. 2, pp. 91-101, 1973.

[2] J. Piskorowski, "Power line interference removal from ECG signal using notch filter with non-zero initial conditions," in Proceedings of the IEEE International Symposium on Medical Measurements and Application (MeMeA '12), pp. 1-3, University of Technology, Budapest, Hungary, May 2012.

[3] S. M. M. Martens, M. M. Mischi, S. G. Oei, and J. W. M. Bergmans, "An improved adaptive power line interference canceller for electrocardiography," IEEE Transactions on Biomedical Engineering, vol. 53, no. 11, pp. 2220-2231, 2006.

[4] G. Duzenlia, Y. Kcili, H. Kuntmanc, and A. Atamanb, "On the design of low-frequency filters using CMOS OTAs operating in the subthreshold region," Microelectronics Journal, vol. 30, no. 1, pp. 45-54, 1999.

[5] T. W. Dawson, K. Caputa, M. A. Stuchly, and R. Kavet, "Pacemaker interference by $60-\mathrm{Hz}$ contact currents," IEEE Transactions on Biomedical Engineering, vol. 49, no. 8, pp. 878886, 2002.

[6] C. Ling, P. Ye, R. Liu, and J. Wang, "A low-pass power notch filter based on an OTA-C structure for electroencephalogram," in Proceedings of the International Symposium on Intelligent Signal Processing and Communications Systems (ISPACS '07), pp. 451453, Xiamen, China, December 2007.

[7] G. Ferri, V. Stornelli, and A. di Simone, "A CCII-based high impedance input stage for biomedical applications," Journal of Circuits, Systems and Computers, vol. 20, no. 8, pp. 1441-1447, 2011. 
[8] C.-D. Tsai, D.-C. Chiou, Y.-D. Lin, H.-L. Chan, and C.-P. $\mathrm{Wu}$, "An active comb filter design for harmonic interference removal," Journal of the Chinese Institute of Engineers, vol. 21, no. 5, pp. 605-610, 1998.

[9] C.-T. Tsai, H.-L. Chan, C.-C. Tseng, and C.-P. Wu, "Harmonic interference elimination by an active comb filter [ECG application]," in Proceedings of 16th Annual International Conference of IEEE Engineering in Medicine and Biology Society, vol. 2, pp. 964-965, Baltimore, Md, USA, November 1994.

[10] A. Fabre, O. Said, F. Wiest, and C. Boucheron, "High frequency applications based on a new current controlled conveyor," IEEE Transactions on Circuits and Systems I: Fundamental Theory and Applications, vol. 43, no. 2, pp. 82-91, 1996.

[11] M. T. Abuelma'atti and N. A. Tasadduq, "New current-mode current-controlled filters using the current-controlled conveyor," International Journal of Electronics, vol. 85, no. 4, pp. 483-488, 1998.

[12] U. Çamam, F. Kaçar, O. Cicekoglu, H. Kuntman, and A. Kuntman, "Novel grounded parallel immittance simulator topologies employing single OTRA," AEU-International Journal of Electronics and Communications, vol. 57, no. 4, pp. 287-290, 2003.

[13] K. N. Salama and A. M. Soliman, "Active RC applications of the operational transresistance amplifier," Frequenz, vol. 54, no. 7-8, pp. 171-176, 2000.

[14] S. Kılınc and U. Çam, "Cascadable all pass and notch filters employing single operational transresistance amplifier," Journal of Computers and Electrical Engineering, vol. 31, no. 6, pp. 391401, 2005.

[15] P. Visocchi, J. Taylor, R. Mason, A. Betts, and D. Haigh, "Design and evaluation of a high-precision, fully tunable OTAC bandpass filter implemented in GaAs MESFET technology," IEEE Journal of Solid-State Circuits, vol. 29, no. 7, pp. 840-843, 1994.

[16] R. L. Geiger and E. Sánchez-Sinencio, "Active filter design using operational transconductance amplifiers: a tutorial," IEEE Circuits and Devices Magazine, vol. 1, no. 2, pp. 20-32, 1985.

[17] S.-H. Yang, K.-H. Kim, Y.-H. Kim, Y. You, and K.-R. Cho, "A novel CMOS operational transconductance amplifier based on a mobility compensation technique," IEEE Transactions on Circuits and Systems II: Express Briefs, vol. 52, no. 1, pp. 37-42, 2005. 

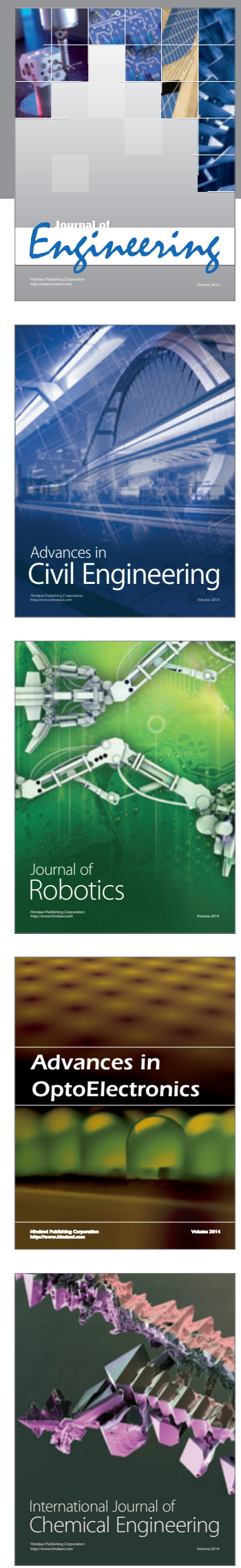

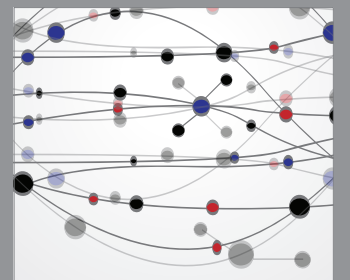

The Scientific World Journal
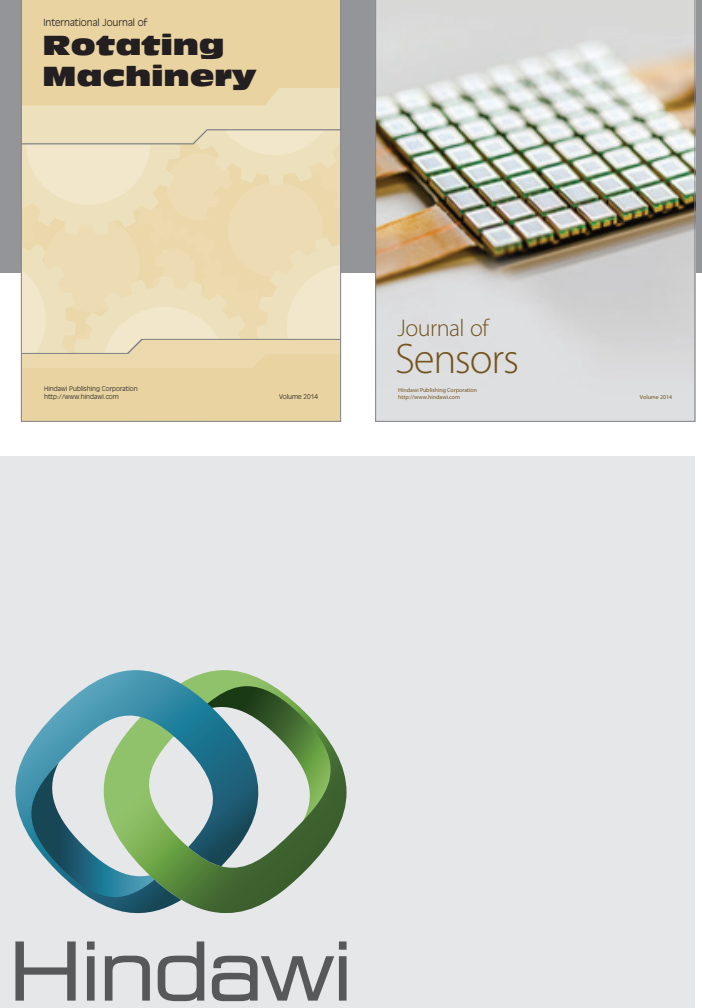

Submit your manuscripts at http://www.hindawi.com
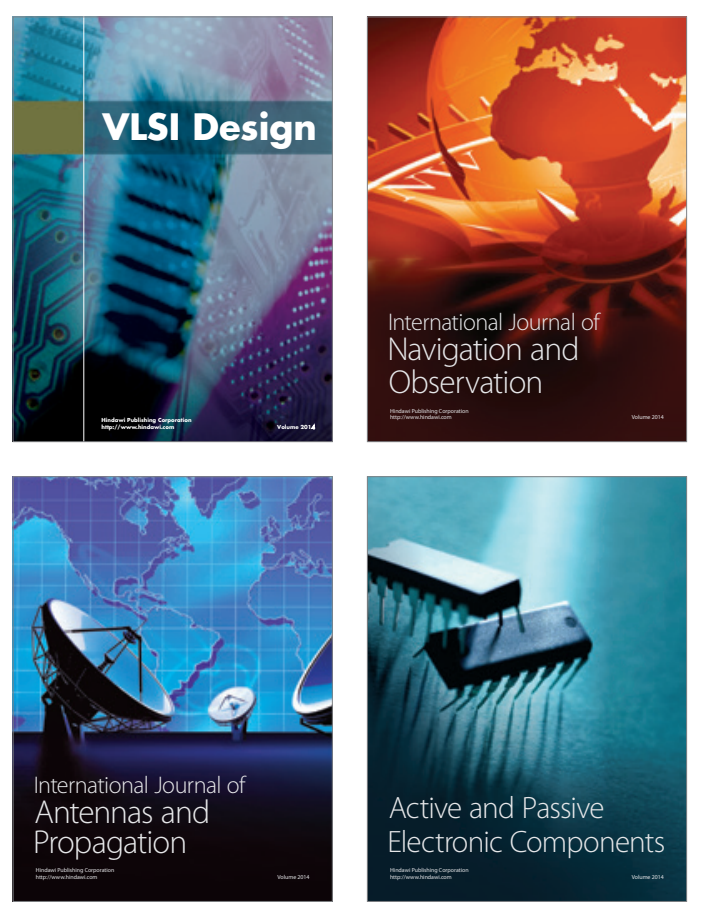
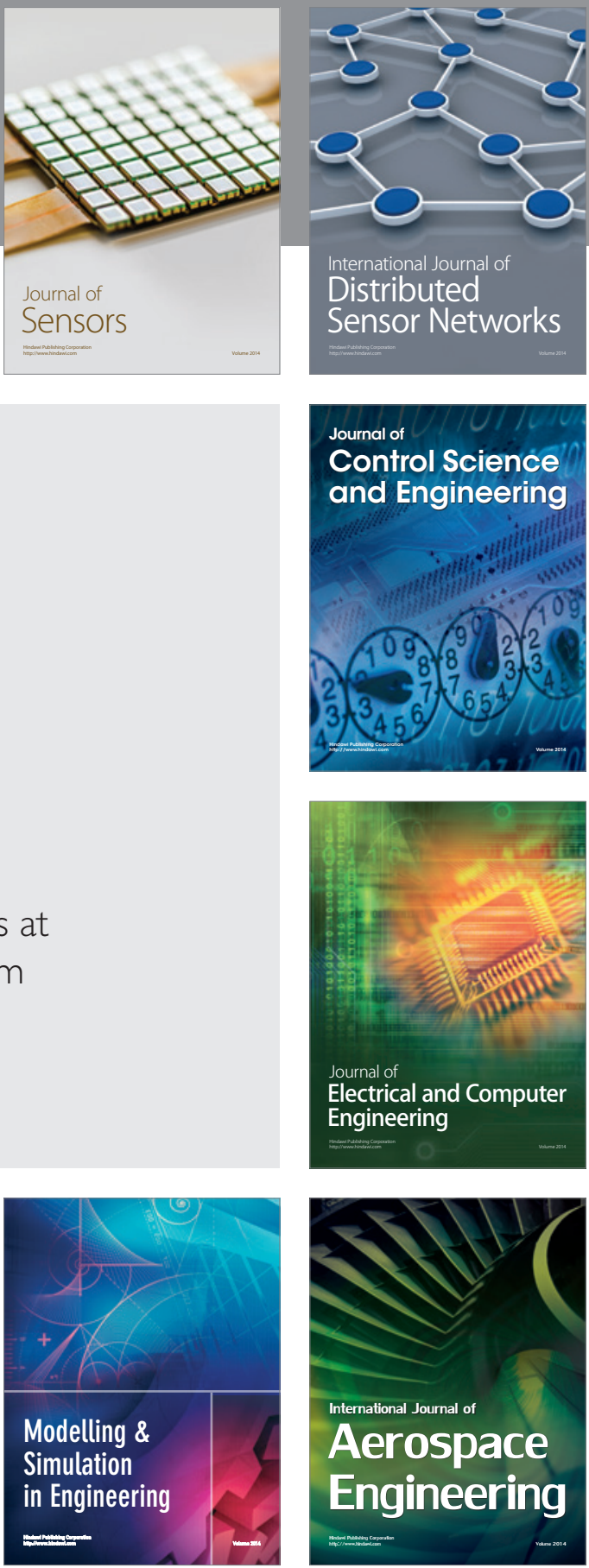

Journal of

Control Science

and Engineering
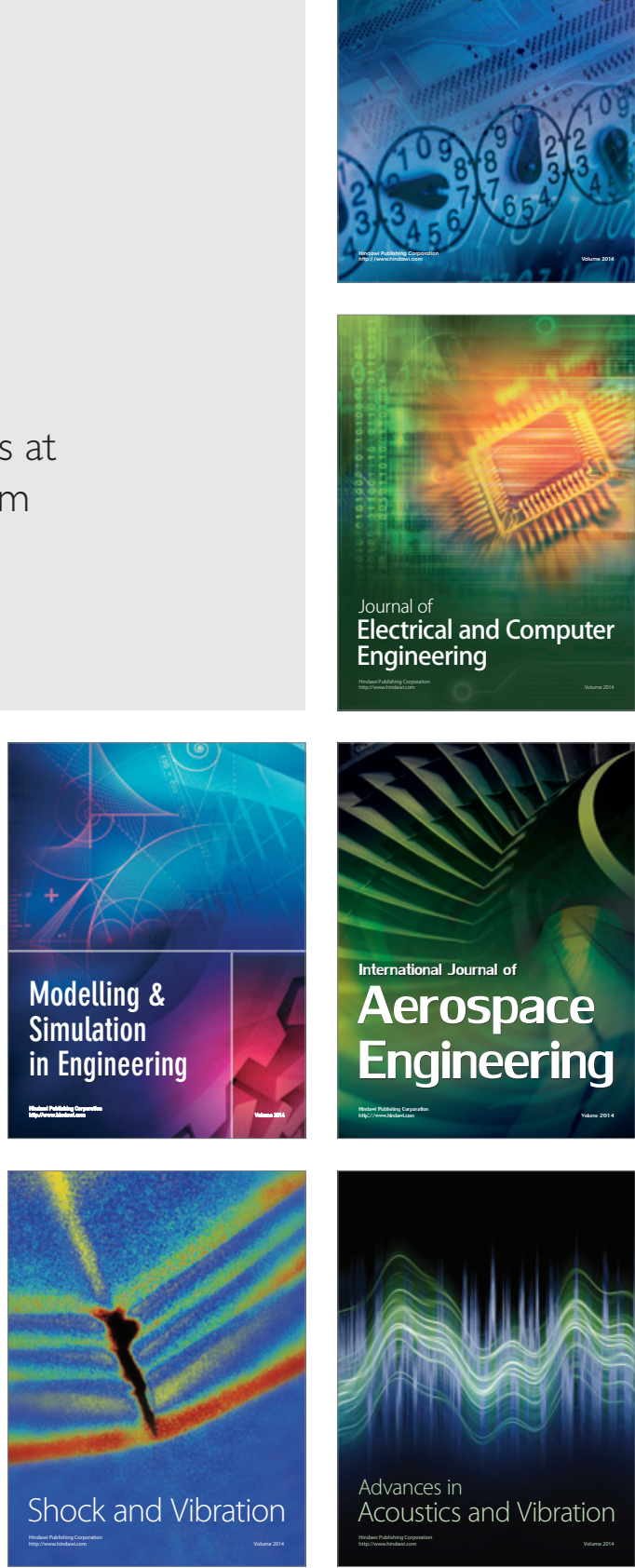